\section{$\underset{\substack{\text { hommes } \\ \text { \& migrations }}}{ }$}

\section{Hommes \& migrations}

Revue française de référence sur les dynamiques

migratoires

1289 | 2011

Les frontières du sport

\title{
Les frontières sportives et leurs agencements en
}

\section{France}

De l'entre-deux-guerres à nos jours

\section{Fabien Sabatier}

\section{(2) OpenEdition \\ Journals}

Édition électronique

URL : http://journals.openedition.org/hommesmigrations/786

DOI : 10.4000/hommesmigrations.786

ISSN : 2262-3353

Éditeur

Musée national de l'histoire de l'immigration

Édition imprimée

Date de publication : 1 janvier 2011

Pagination : 6-9

ISSN : 1142-852X

Référence électronique

Fabien Sabatier, "Les frontières sportives et leurs agencements en France », Hommes \& migrations [En ligne], 1289 | 2011, mis en ligne le 31 décembre 2013, consulté le 14 novembre 2019. URL : http:// journals.openedition.org/hommesmigrations/786; DOI : 10.4000/hommesmigrations.786 


\title{
Les frontières sportives et leurs agencements en France
}

\section{De l'entre-deux-guerres à nos jours}

\author{
Par Fabien Sabatier, \\ maître de conférences, université de Bordeaux-2, LACES \\ (Laboratoire cultures, éducation, sociétés) EA 4140
}

Les chercheurs ${ }^{(1)}$ impliqués dans ce numéro sont animés par la volonté de cerner le rôle du sport dans la formation ou l'effacement des frontières en société. La "frontière" renvoie au terme de "boundary" popularisé par les travaux de Fredrik Barth $^{(2)}$ à la fin des années soixante dans le champ de l'anthropologie sociale. L'histoire contemporaine fait aujourd'hui une place à cette notion dans le champ des études postcoloniales en France ${ }^{(3)}$ en s'attachant à décrire et à comprendre la formation des limites qui façonnent la condition minoritaire dans sa relation à l'histoire croisée de la colonisation et de l'immigration. L'approche proposée dans le cadre de cette contribution collective se conçoit de façon plus extensive. Elle n'aborde pas exclusivement la thématique minoritaire de la postcolonie, mais, plus largement, le rôle du sport en France dans la "régulation" de l'altérité liée aux rencontres migratoires, de l'entre-deux-guerres à nos jours.

Si le sport est bien un phénomène de civilisation $^{(4)}$ et de culture ${ }^{(5)}$, sa diffusion planétaire résulte pour beaucoup de migrations internationales et en particulier de l'expansion coloniale européenne. Depuis une longue décennie, avec un certain retard français sur la recherche anglo-saxonne, les "formes sportives" prises par la réunion de populations allochtones et autochtones, majoritaires ou minoritaires, sont débattues au sein de la communauté scientifique.

Différents numéros de revues françaises ${ }^{(6)}$ ou anglo-saxonnes ${ }^{(7)}$ et des ouvrages ${ }^{(8)}$ rendent compte des travaux conduits et tentent d'apprécier les dynamiques du changement social et culturel à l'échelle de la France et du monde. Ainsi, dans leurs rapports au 
sport, les thèmes de la médiation, de l'intégration, de l'indigénisation et du métissage irriguent bon nombre d'écrits de facture anthropologique, historique, sociologique ou issus du champ des cultural studies $^{(9)}$.

Dans une veine pluridisciplinaire, la dizaine d'articles composant ce dossier présentent des résultats de recherche qui valident la grande plasticité du sport face à la diversité des contextes historiques dans lesquels il est utilisé. Loin d'être un moyen universel de réunion entre populations mises en contact par l'Histoire, il est façonné par les enjeux et les contextes locaux au sein desquels il se développe, et représente pour différents acteurs une ressource de premier ordre. Les trois terrains distincts de la situation coloniale dans l'Empire français, de l'immigration européenne dans l'Hexagone et de la France postcoloniale sont "sondés" par les différents contributeurs. Ces derniers abordent successivement des cas d'usages sportifs prescrits ou réels qui agencent les frontières entre des communautés humaines de dimension nationale, ethnique ou sociale dans des situations migratoires et postmigratoires singulières.

Les trois premières contributions traitent de la situation coloniale ${ }^{(10)}$ et visent à enrichir une historiographie balbutiante sur les terrains d'étude distincts de la sociologie coloniale, du militantisme communiste français et du combat indépendantiste.

Jean-Paul Callède, sociologue du sport, en présentant la position de René Maunier ${ }^{(11)}$, figure du droit et de la sociologie coloniaux, exhume un aspect méconnu de la bibliothèque coloniale ${ }^{(12)}$. Il montre comment ce défenseur de la colonisation envisageait, au cours de l'entre-deux-guerres, les apports positifs des jeux et du sport en situation de "culture-contact". Évelyne Combeau-Mari évoque les enjeux du transfert culturel du rugby chez les élites mérina au cours des années trente-cinquante à Madagascar. Loin de favoriser sur le moyen terme un espace de contact avec le colonisateur, cet usage fut envisagé comme un vecteur de développement physique et moral utile à l'émancipation nationale ${ }^{(13)}$. Fabien Sabatier traite, pour l'essentiel, de l'engagement colonial, mais également antiraciste et postcolonial des organisations sportives communistes de France. Oscillant entre la défense de l'émancipation nationale ou simplement sociale des populations colonisées, la population algérienne en particulier, ces fédérations affinitaires ont longtemps opéré des choix dictés par leurs tutelles politiques internationales ou nationales.

La deuxième rubrique de ce dossier traite des immigrations européennes en France métropolitaine. Différentes formes d'“entre-soi sportifs" sont présentées pour des immigrations présentant des niveaux d'intégration différents. Ces historiens complètent les travaux déjà existants sur l'immigration polonaise ${ }^{(14)}$ et italienne ${ }^{(15)}$ en particulier. Karen Bretin présente le cas des Polonais de Montceau-les-Mines au détour des années trente. Cette historienne montre comment ce bassin minier 
amplement dévolu à la cause du sport communiste interagit avec une immigration de culture catholique et anticommuniste, dès lors très soucieuse d'élaborer son propre réseau sportif. Tony Froissart aborde, pour une période similaire, le cas des Italiens d'Argenteuil, immigrés antifascistes proches des communistes français. Leur vie sociale, partagée entre pratiques d'appartenance communautaire, syndicale, politique ou familiale, montre que la scansion de leur quotidienneté témoigne d'une pluralité de sociabilités existantes, où l'antifascisme, vecteur d'intégration, ne fait au bout du compte qu'effleurer des pratiques sportives en fait étroitement liées à une sociabilité populaire, festive et parfois communautaire. Rémi Solacroup propose une immersion dans le réseau sportif portugais en région bordelaise au cours des dernières décennies. Il souligne la relative vigueur d'une "portugalité" sportive soucieuse de répondre à la pérennité d'enclaves associatives portugaises pour une immigration déjà ancienne. Ces immigrés et leur descendance, considérés comme bien intégrés, usent ainsi du sport longtemps après la phase principale de migration.

Le dernier temps de ce numéro questionne plus spécifiquement les situations postcoloniales ${ }^{(16)}$. Les auteurs présentent différentes utilisations du sport comme un rouage de l'affirmation identitaire et dépassent ainsi le strict registre de l'intégration. Éric Claverie étudie le sport malgache dans l'Hexagone depuis la décennie soixantedix. En "interrogeant" le rassemblement sportif national malgache, il confirme l'utilité du sport associatif dans l'évitement du désenchaînement des générations en situation diasporique ${ }^{(17)}$. Stanislas Frenkiel discute le désir d'Algérie chez les sportifs français d'origine algérienne, confrontés aux scories du colonial, et dès lors devenus joueurs de l'équipe nationale des Fennecs à partir des années quatre-vingt. JeanFrançois Bruneaud questionne la société martiniquaise en s'arrimant à la figure du "métro" dans l'espace des pratiques du corps, ce spécialiste de l'ethnicité conclut à l'improbable "désethnicisation" d'une société profondément fragmentée par les frontières phénotypiques. Quant à Maguy Moravie, en étudiant la yole ronde sur ce même territoire d'outre-mer, elle montre la double "nature" de ce sport "pieds nus" à la fois marqué par des ethnicités historiquement constituées, mais également susceptible d'être une ressource utile à l'invention d'une identité spécifiquement martiniquaise.

Ainsi, la grande porosité des pratiques corporelles et sportives aux configurations historiques et spatiales ouvre une fenêtre sur les dynamiques culturelles, politiques, sociales passées et présentes nées des contacts migratoires. Loin du discours sur une supposée essence intégrative du sport, il est à la fois signe, ressource et dès lors forme d'“agencement" de la "rencontre". Ses multiples usages revitalisent, fabriquent ou tentent d'effacer des frontières face à une pluralité de processus à l'ceuvre dans le monde contemporain. 
1. Membres de différents laboratoires de recherche habilités (LACES, ISOS, CRESOI, CERHIC, GEMASS, CRIS) et d'un groupe de recherche composé de chercheurs issus pour l'essentiel de ces différentes équipes (GRESAM), ces historiens, sociologues et ethnologues travaillent sur la thématique des pratiques du corps et des migrations.

2. Barth Fredrik, Ethnic Groups and Boundaries. The Social Organization of Culture Difference, London, George Allen \& Uwin, 1969.

3. Fassin Didier (dir), Les Nouvelles Frontières de la société française, Paris, La Découverte, 2010, p. 6.

4. Norbert Elias, Dunning Éric, Sport et civilisation. La violence maîtrisée, Paris, Fayard, 1994 (1986).

5. Guttmann Allen, From the Ritual to Record. The Nature of Modern Sports, New York, Columbia University Press, 1978.

6. La CNHI, le CIEMI et l'association Génériques, et leurs revues respectives, Hommes ひ Migrations, Migrations, Société et Migrance. Notons dans une veine plus anthropologique : Corps et Culture, "Métissages", n 6/7, 2004.

7. International Journal of the History of Sport, "Sport in the Pacific: Colonial and Postcolonial Consequences", vol. 26, Routledge, 2009.

8. En particulier les publications suivantes : Dumont Jacques, Sport et assimilation à la Guadeloupe, Paris, L'Harmattan, 2002. Combeau-Marie Évelyne, (dir.), Sports et loisirs dans les colonies, XIX'e - XX' siècles, Paris, Le Publieur, 2004.

9. Appadurai Arjun, Après le colonialisme. Les conséquences culturelles de la globalisation culturelle, Paris, Payot, 2001.

10. Balandier Georges, "La situation coloniale : approche théorique", in Les Cahiers internationaux de sociologie, vol. 11, 1951, pp. 44-79.

11. Particulièrement critiqué aujourd'hui pour ses visées colonialistes, voir sur ce second point Lecour-Grandmaison Olivier, De l'indigénat. Anatomie d'un "monstre” juridique : le droit colonial en Algérie et dans l'Empire français, Paris, La Découverte, coll. "Zones”, 2010.

12. Coquery-Vidrovitch Catherine, Enjeux politiques de l'histoire coloniale, Marseille, Agone, 2009.

13. À l'instar des publications suivantes pour l'AOF, l'Algérie et l'Indochine, Deville-Danthu Bernadette, Le Sport en noir et blanc. Du sport colonial au sport africain dans les anciens territoires français d'Afrique occidentale, (1920-1965), Paris, L'Harmattan, collection "Espaces et Temps du Sport”, 1997, et Bancel Nicolas, Denis Daniel et Fates Youssef (dir.), De l'Indochine à L'Algérie, la jeunesse en mouvement des deux côtés du miroir colonial, 1940-1962, Paris, La Découverte, 2003.

14. Fontaine Marion, "La polonité face à la sécularisation dans le monde minier lensois", communication au colloque international "Migrations, religions et sécularisation". L'impact des migrations sur les modèles nationaux (Europe et Amérique du Nord)", Paris, 2005.

15. Favero Jean-Pierre, Immigration et intégration. Le cas des Italiens dans le bassin de Briey (fin XIX siècle - années quarante), Paris, L'Harmattan, 2008.

16. Celles-ci s'entendent à la fois comme chronologie de ce qui succède à la période coloniale et comme processus historiques qui découlent de la colonisation.

17. Attias-Donfus Claudine, Wolff François-Charles, Le Destin des enfants d'immigrés. Le désenchaînement des générations, Paris, Stock, 2009. 